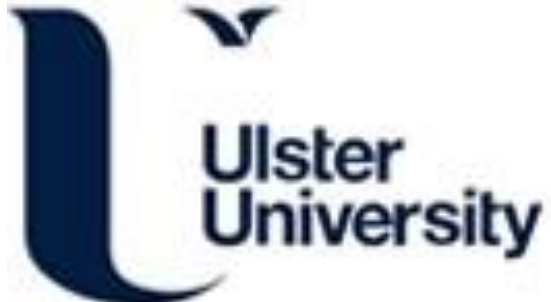

High density nanowire electrodes for Intracortical microstimulation

Puttaswamy, S., Shi, Q., Steele, D., Fishlock, S., Lee, C., \& McLaughlin, J. (Accepted/In press). High density nanowire electrodes for Intracortical microstimulation. In IEEE EMBC 2019 IEEE Xplore.

Link to publication record in Ulster University Research Portal

Published in:

IEEE EMBC 2019

Publication Status:

Accepted/In press: 14/05/2019

\section{Document Version}

Author Accepted version

\section{General rights}

Copyright for the publications made accessible via Ulster University's Research Portal is retained by the author(s) and / or other copyright owners and it is a condition of accessing these publications that users recognise and abide by the legal requirements associated with these rights.

\section{Take down policy}

The Research Portal is Ulster University's institutional repository that provides access to Ulster's research outputs. Every effort has been made to ensure that content in the Research Portal does not infringe any person's rights, or applicable UK laws. If you discover content in the Research Portal that you believe breaches copyright or violates any law, please contact pure-support@ulster.ac.uk. 


\title{
High density nanowire electrodes for Intracortical microstimulation
}

\author{
Srinivasu Valagerahally Puttaswamy, ${ }^{\mathrm{a}, \mathrm{b}}$, Qiongfeng Shic ${ }^{\mathrm{c}}$, David Steele ${ }^{\mathrm{a}}$, Sam Jeffery Fishlock ${ }^{\mathrm{a}}$ \\ Chengkuo Lee ${ }^{\mathrm{b}, \mathrm{c}}$ and James McLaughlin ${ }^{\mathrm{a}}$
}

\begin{abstract}
High-density electrodes with the nano feature size greatly enhance resolution and specificity during intracortical microstimulation. In this viewpoint, we fabricated and developed high-density nanowire (NW) electrodes, $\sim 2.45 \times 10^{9}$ / $\mathrm{cm}^{2}$ that could directly stimulate specific region of the cortex with low current amplitude in the range of 120-180 $\mu \mathrm{A}$. The proposed nanowire electrodes will help expand the capabilities of microstimulation and extend the range of dysfunctions that can be treated using microstimulation technique.
\end{abstract}

\section{INTRODUCTION}

In the 1870 s, experiments were performed in which regions of the canine cortex where electrically stimulated[1]. Careful correlation of limb responses together with duration and location of stimulation indicated that areas of the body could be approximately mapped to a region within the motor cortex. We now know this to be the somatosensory cortex and since then have more fully developed the concept of a somatotopic map for a variety of organisms [2]. Early maps were created by placing comparatively large electrodes directly on the cortical surface at multiple positions. Resolution of such maps were limited due to the overlapping of multiple structural regions of excitation. This was later improved by development of the intracortical microstimulation (ICMS) technique, in which microelectrodes were inserted directly into cortical tissue. This facilitated the targeting of specific layers within the cortex, as well as a reducing the current required to effect stimulation [3]. The practical outcome has not only been the creation of higher resolution maps, but a development in the field of microstimulation. This holds promise for the development of techniques and devices to enable management of chronic pain [4] or to restore tactile sensation in patients following nerve damage [5].

Conventionally, microelectrodes are fabricated by using a semiconductor fabrication process employed for neural stimulation and recording. Silicon-based microelectrodes were used as cortical probes [6] and later, complementary metal-oxide-semiconductor (CMOS) technology led to the integration of electronics with electrodes [7]. However, these microelectrodes are larger than cell body in size, causing damage to cells and surrounding tissue during electrode penetration [8]. In addition, the gap between individual electrodes in electrode arrays may result in a low spatial resolution [9]. On the other hand, nanoelectordes are considered as an alternative to conventional electrodes since they provide many advantages [10].

${ }^{a}$ Connected Health Innovation Centre, Engineering Research Institute,

Ulster University,

Newtownabbey, United Kingdom

${ }^{\mathrm{b} S}$ Singapore Institute for Neurotechnology

Centre for Life Sciences, National University of Singapore
In recent time, fabrication technology of nanoscale electrodes has been greatly advanced, which might evolve neuroscience research and clinical therapy [11]. Nanoengineered devices with nanoelectrodes have the capability to interact with biological systems on a molecular scale, offering remarkable levels of control over physiological activity as all bio-system components have nanoscale dimensions [12]. Ideally, stimulation devices should have high-density nanoelectrodes, capable of achieving specificity of stimulation to the level of individual cells to treat medical disorders [13]. It has been reported that electrodes can be made small enough to penetrate the cellular membrane to record or stimulate individual cells, without affecting cell viability [14]. Nano sized electrodes offer advantages such as minimum cell-to-electrode distance and better resolution [15]. Nanoelectrodes have been grown epitaxially for cortex stimulation and recording $[16,17]$.

In this work we have successfully fabricated high density zinc oxide nanowires ( $\mathrm{ZnO} \mathrm{NWs}$ ) with optimized growth parameters for microstimulation application. Previous work on $\mathrm{ZnO} \mathrm{NWs}$ reported that they were biocompatible and biosafe, potentially suitable for biomedical applications [18]. Wide range of methods are employed to fabricate $\mathrm{ZnO}$ NWs, we have used simple, low temperature, hydrothermal method with a controllable nanomorphology. The fabricated high density $\mathrm{ZnO} \mathrm{NWs}$ can be effectively used for low current, ICMS application.

\section{MATERIALS AND METHODS}

\section{A. Fabrication of $\mathrm{ZnO} \mathrm{NW}$ electrodes.}

$\mathrm{ZnO} \mathrm{NWs}$ were fabricated by hydrothermal method, with fabrication steps explained in detail in our previous work[19] . In summary, the supporting substrate was ultrasonically cleaned for $10 \mathrm{~min}$ before the seeding step and dried with nitrogen gas. Pulse laser deposition (PLD) technique was used to coat $100 \mathrm{~nm}$ thickness $\mathrm{ZnO}$ layer, as a seed layer for hydrothermal $\mathrm{ZnO} \mathrm{NWs}$ growth. The seeded substrate was immersed into the growth solution, maintained at $90^{\circ} \mathrm{C}$ in a conventional oven. the substrate was taken out of the solution, rinsed with DI water and then dried with nitrogen gas. growth parameters were optimized to grow NWs of high density on microwire of $75 \mu \mathrm{m}$ diameter $(20 \mu \mathrm{m}$ at the tip, made of $90 \%$ platinum $/ 10 \%$ iridium and insulated with polyimide; from California Fine Wire, CA, USA).

${ }^{\mathrm{c} D e p a r t m e n t}$ of Electrical and Computer Engineering, National University of Singapore email: srini@ulster.ac.uk 


\section{B. Electrodeposition}

In the final stage, the $\mathrm{ZnO}$ NWs were electrodeposited with iridium oxide $\left(\mathrm{IrO}_{2}\right)$ to increase the cathodic charge storage capacity (CSCc) for facilitating low current microstimulation [20]. The $\mathrm{IrO}_{2}$ has high charge storage capacity due to its high surface roughness and reversible faradaic reactions it undergoes [21]. To prepare the solution, $300 \mathrm{mg}$ iridium chloride was dissolved in $200 \mathrm{ml}$ of DI water and stirred for $15 \mathrm{~min}$. Additionally, $1000 \mathrm{mg}$ oxalic acid powder was added to the solution and then stirred for $10 \mathrm{~min}$. Potassium carbonate was gradually added to the solution to maintain a $\mathrm{pH}$ value of 10.5 . The prepared solution was maintained at room temperature for about two days before use, and its color turned to violet during this process. It was then stored in a dark bottle at $4^{\circ} \mathrm{C}$ for future use. During the process of electrodeposition, electrode pads were connected to the negative terminal of an external voltage source while electrode sites immersed in the prepared solution. Platinum mesh electrode immersed in the solution was connected to positive terminal of the external voltage source. Pulsed voltage, with peak-to-peak magnitude of $3 \mathrm{~V}$ and bias voltage of $1.5 \mathrm{~V}$, was applied for $3 \mathrm{~min}$ to electroplate $\mathrm{IrO}_{2}$. The $\mathrm{IrO}_{2}$ was directly deposited on the nanowire part. The thickness of $\mathrm{IrO}_{2}$ film was approximately $100 \mathrm{~nm}$.

\section{Electrochemical characterization of $\mathrm{ZnO} \mathrm{NW}$ electrodes}

The experimental set up for the measurement of electrochemical properties is shown in Fig. 1(a). The NW electrodes at the tip of PtIr microwire is used as a working electrode (WE), whereas Pt mesh as counter electrode (CE) and $\mathrm{Ag} / \mathrm{AgCl}$ as the reference electrode (RE). These three electrodes were immersed into the phosphate-buffered saline (PBS) solution $(\mathrm{pH}=7)$. Impedance measurements were carried out in the frequency range of $1 \mathrm{~Hz}-10 \mathrm{kHz}$ with an excitation input voltage of $10 \mathrm{mV}$. Output impedance was measured with an impedance analyzer (Zennium E, ZAHNER elektrik Inc, Germany). The electrochemical potential of the electrode swept from $-0.6 \mathrm{~V}$ to $0.8 \mathrm{~V}$ vs an $\mathrm{Ag} / \mathrm{AgCl}$ reference electrode at $50 \mathrm{mV} / \mathrm{s}$ while plotting $\mathrm{CV}$ for the $\mathrm{NW}$ electrode electrodes $(n=6)$. The CSCc value was calculated using time integral of the cathodic current during cyclic voltammetry process.

\section{RESULTS AND DISCUSSION}

\section{A. Electrochemical measurements}

Characterization of an electrochemical interface during ICMS is very important as electrodes with lower impedance are better suited for stimulation [22]. Furthermore, if charge injection capacity of is low, high current amplitudes will be required to stimulate during ICMS. The high amplitude stimulus causes fatigue or delamination of the electrodes surface due to unwanted redox reactions [23]. Lower impedance electrodes also minimize heat generation at the interface, which is critical to prevent cell damage during ICMS. The mean impedance of $\mathrm{IrO}_{2}$ coated, $\mathrm{ZnO}$ NWs electrode was $1 \mathrm{k} \Omega$ at $1 \mathrm{kHz}$ (Fig. 1(b)), which is significantly lower than non-coated electrodes, suitable for ICMS. Additionally, it shows a small capacitive phase angle for $\mathrm{IrO}_{2}$ coated, $\mathrm{ZnO} \mathrm{NW}$ selectrode at low frequencies (Fig. 1(c)) compared to bare electrode. The mean cathodic charge storage capacity (CSCc) was 26.59 $\mathrm{mC} / \mathrm{cm}^{2}$ indicated by the cathodic area of the $\mathrm{CV}$ plot (Fig. 2(d)). The results demonstrate that fabricated NW electrodes coated with $\mathrm{IrO}_{2}$ is appropriate for in vivo ICMS. (a) Experimental set up

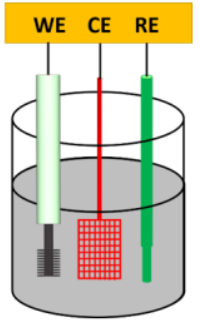

(c) Phase angle

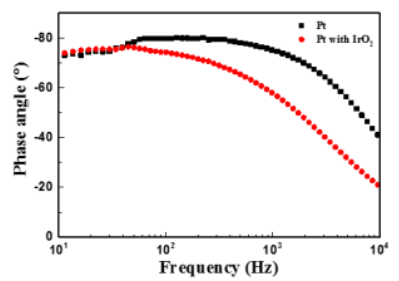

(b) Impedance

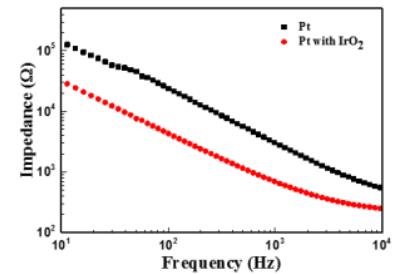

(d) Cyclic voltammetry

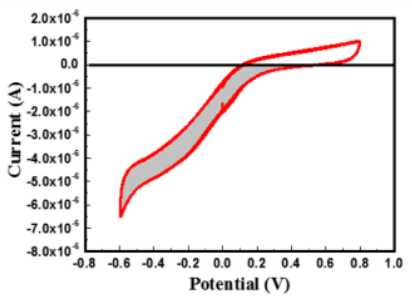

Fig.1. Electrochemical impedance spectroscopy (EIS) and cyclic voltammetry (CV) test. (a) experimental set up with different components. The results of EIS (b) impedance measurement for $\mathrm{IrO}_{2}$ coated and noncoated electrodes and (c) phase angle comparison for $\mathrm{IrO}_{2}$ coated and noncoated electrodes. (d) results of $\mathrm{CV}$ for the NW electrodes electrodeposited with $\mathrm{IrO}_{2}$.

\section{B. Optimization of aspect ratio of $\mathrm{ZnO} \mathrm{NW}$ s electrodes}

The influence of PEI concentration on NW diameter, length and aspect ratio is depicted in Fig. 2. The amount of PEI varied from 0 to $1 \mathrm{~g}$ and morphology of NW in each condition is shown. It was evident that the growth of NWs was very poor, in the forms of clusters, with a very low aspect ratio with the absence of PEI (Fig. 2(a)) The NW diameter was reduced when the amount of PEI increased from 0.3 to $0.6 \mathrm{~g}$ (Fig. 2(b-e)). However, there was a marginal improvement in the aspect ratio (Fig. 2(k)). When the PEI amount was increased to $0.7 \mathrm{~g}$, NWs were upright, consistent over the entire area (Fig. 2(f)) and the aspect ratio in this condition was highest (Fig. 2(k)). This is because the PEI molecules are deposited on the lateral facets of the $\mathrm{ZnO}$ NWs, causing the lateral growth of the NWs to be largely limited. Further increase in PEI from 0.7 to $1 \mathrm{~g}$ (Fig. 2(g, h)) led to the forming of clusters at a few places, resulting in a significant drop in the aspect ratio (Fig. 2(k)). This may be due to the overwhelming amount of PEI coordinating with $\mathrm{Zn}^{2+}$, decreasing the $\mathrm{Zn}^{2+}$ left in the solution for $\mathrm{ZnO} \mathrm{NW}$ growth to take place. 
The diameter of $\mathrm{ZnO}$ NW was reduced when PEI amount increased in the growth solution (Fig. 2(i)). This is because the PEI molecules get adsorbed on the lateral facets of the $\mathrm{ZnO}$ NWs, causing the lateral growth of the NWs to be largely limited as explained before. When the amount of PEI was increased up to $0.7 \mathrm{~g}$ in the growth solution, the NW diameter seemed to be constant since PEI molecules are enough to cover the complete lateral facets of $\mathrm{ZnO}$ NWs. As shown in Fig. 2(j), when the amount of PEI increased from $0.7 \mathrm{~g}$ onwards, length of $\mathrm{ZnO} \mathrm{NW}$ started to decrease. This may be due to the overwhelming amount of PEI coordinating with $\mathrm{Zn}^{2+}$, decreasing the $\mathrm{Zn}^{2+}$ left in the solution for $\mathrm{ZnO} \mathrm{NW}$ growth to take place. Thus, $0.7 \mathrm{~g}$ PEI seemed to be the optimized condition for growth of $\mathrm{ZnO} \mathrm{NW}$ with high aspect ratio by using this recipe. The density of $\mathrm{ZnO} \mathrm{NW}$ was $2.45 \times 10^{9} / \mathrm{cm}^{2}$, which is of high density.

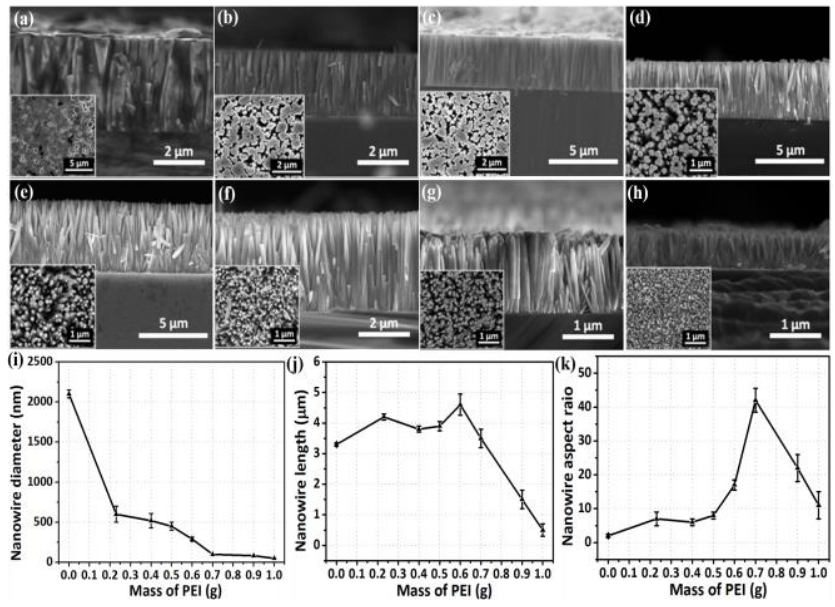

Fig. 2. Influence of PEI on aspect ratio of nanowire. Morphology of nanowires with different concentration of PEI (a) with the absence of PEI (b, $\mathrm{c}, \mathrm{d}, \mathrm{e})$ varying concentration from 0.2 to $0.6 \mathrm{~g}$ with a marginal increase in aspect ratio, (f) substantial increase in aspect ratio with $0.7 \mathrm{~g}(\mathrm{~g}, \mathrm{~h})$ gradual decrease in aspect ratio with increased concentration of PEI from 0.9 to $1 \mathrm{~g}$. Variation of (i) diameter, (j) length and $(\mathrm{k})$ aspect ratio of $\mathrm{NW}$ with different concentration of PEI.

\section{Optimization of growth time of $\mathrm{ZnO} \mathrm{NW}$ electrodes}

The influence of growth time on growth parameters has been investigated. The optimized mass of $0.7 \mathrm{~g}$ PEI was added in the growth solution while $0.4 \mathrm{~g}$ PEI was used as a control for comparison. SEM images in Fig 3(a-f) represent the side view of the $\mathrm{ZnO} N W$ s grown in the two different PEI solution with varying growth time of 3,4 and $5 \mathrm{hr}$. The inset SEM images show the corresponding top view of the $\mathrm{ZnO} \mathrm{NWs}$. Plots of $\mathrm{ZnO} \mathrm{NW}$ diameter, length, and aspect ratio vs growth time are shown in Fig. 3(g-i), respectively. The length of $\mathrm{ZnO}$ NW continuously increased with growth time as shown in Fig. 3(h), since the vertical growth of $\mathrm{ZnO} \mathrm{NW}$ was not hindered. However, PEI is adsorbed on the lateral facets of $\mathrm{ZnO} \mathrm{NW}$ hindering lateral growth. Compared to $0.4 \mathrm{~g}$ PEI, $0.7 \mathrm{~g}$ PEI seems more effective to constrain the lateral growth. The diameter of $\mathrm{ZnO} \mathrm{NW}$ with $0.7 \mathrm{~g}$ PEI was almost constant with growth time and as a result, the aspect ratio of $\mathrm{ZnO} \mathrm{NW}$ continues to increase with growth time.
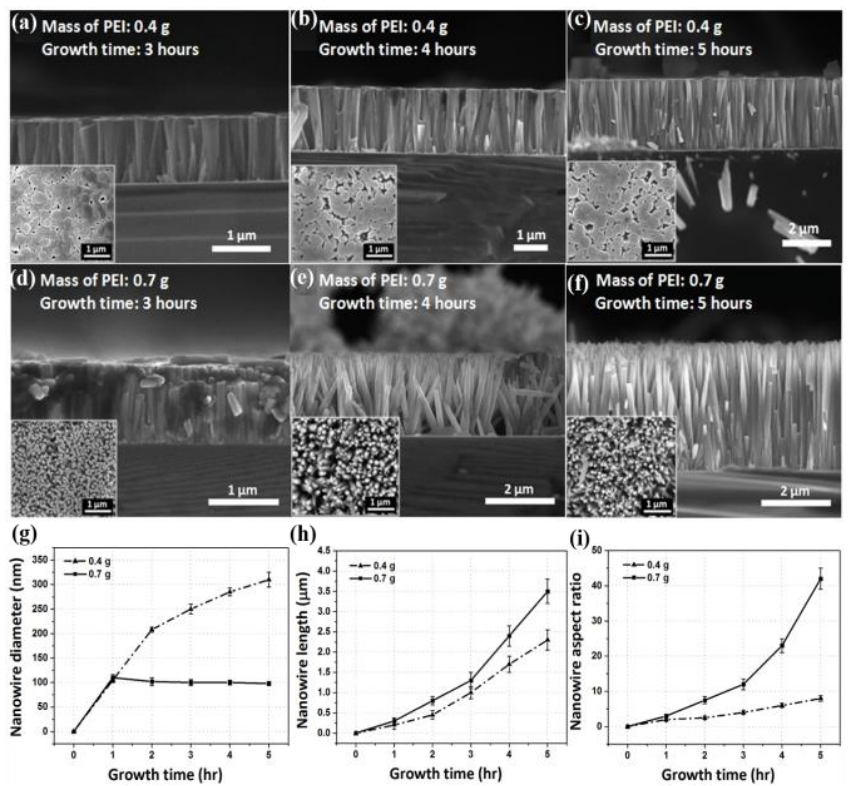

Fig. 3. Influence of growth time on Zno growth parameters. (a) - (f) SEM images showing the side view of the $\mathrm{ZnO}$ NWs grown with different growth time of 3,4 and $5 \mathrm{hr}$, for 0.4 and $0.7 \mathrm{~g}$ PEI concentrations. The inset SEM images show the respective top view of the $\mathrm{ZnO}$ NWs. Plot of $\mathrm{ZnO} \mathrm{NW}(\mathrm{g})$ diameter, (h) length and (i) aspect ratio, versus growth time for 0.4 and $0.7 \mathrm{~g}$ PEI

High degree of control over the NWs geometry (NWs position, length, and diameter) was precisely achieved by optimizing PEI concentration and growth time. ZnO NWs electrodes fabricated exhibit many advantages compared to conventional stimulation electrodes. The scaled down size of NWs can achieve interface at a single cell level and reduce inflammatory response without sacrificing the ability to transfer charge to a cell which is critical for improving stimulation. NW electrodes with high surface area can significantly enhance charge injection capacity in vivo [24] with reduced interfacial impedance, which is imperative during micro stimulation. The longer and high aspect ratio NWs will have an enhanced flexibility, to withstand tissue movement in vivo. It will provide significantly better coupling between electrode and tissue increasing charge injection.

\section{Cortical microstimulation}

An adult female Sprague Dawley rats, weighing 250-300 g (In Vivos Pte Ltd, Singapore) were used in this study. Before experiment, the rats were housed for one week with food and water under day-light simulated conditions (12 hours light on/off). The temperature was maintained at $22 \pm$ $1^{0} \mathrm{C}$. The animal experiments were approved by Agri-Food \& Veterinary Authority of Singapore (AVA), ethics commission, the Institutional Animal Care and Use Committee (IACUC) of National University of Singapore. Single bolus injection of ketamine/xylazine $(150 \mathrm{mg} / \mathrm{kg}$ and $10 \mathrm{mg} / \mathrm{kg}$, respectively, intraperitoneal) was administered for maintenance of anesthesia. After an adequate depth of anesthesia was reached, we performed $10 \times 4 \mathrm{~mm}$ craniotomy using dental drill, while the animal's head was fixed in a stereotaxic apparatus. 
$\mathrm{ZnO} \mathrm{NW}$ bipolar electrodes on the tip of platinum/iridium microwire were inserted to a depth of 1.5 $\mathrm{mm}$ from the cortical surface. The diameter platinum/iridium microwire at the tip was $20 \mu \mathrm{m}$. The size of the NWs tapers from around 50 to $250 \mathrm{~nm}$ at the bottom to less than 30 to 150 $\mathrm{nm}$ at the top. The length of the NWs was about $5 \mu \mathrm{m}$ with an aspect ratio about 20 to 96 . Biocompatible hydrogel poly (ethylene glycol) diacrylate (PEGDA) thin film of thickness $100 \mu \mathrm{m}$ was fabricated $[25,26]$ immediately after inserting electrodes. Cortical stimulation was carried out with stimulation parameters consisted of $20 \mu$ s pulse, at a frequency of $300 \mathrm{~Hz}$, with amplitudes varying between 120 $180 \mu \mathrm{A}$ and 10 pulse trains/sec. We investigated hindlimb movement while stimulating cortex with above parameters. We observed the complex movement of hip, knee and ankle joint together at the same time. We could observe this movement with low stimulus current even at $120 \mu \mathrm{A}$.

\section{CONCLUSIONS}

In this work, we successfully, optimized growth parameters to fabricate high density nanowire electrode suitable for cortical stimulation. Low stimulus current, results in complex hindlimb movement attributed to the increased electrode active surface area formed during fabrication of nanostructured electrodes. The precise, sensitive and localized cortical microstimulation achieved in this study promises a future application of a fully implantable NW electrode array for ICMS.

\section{ACKNOWLEDGMENT}

This work was supported by grants from National Research Foundation (NRF) CRP project 'Peripheral Nerve Prostheses: A Paradigm Shift in Restoring Dexterous Limb Function' (R-719-000-001-281) and funding under the Invest Northern Ireland and the European Union's INTERREG VA Programme, managed by the Special EU Programmes Body (SEUPB) under the Connected Health Innovation Centre (CHIC) competence center

\section{REFERENCES}

[1] G. Fritsch, E. Hitzig, Electric excitability of the cerebrum (Über die elektrische Erregbarkeit des Grosshirns), Epilepsy Behav. 15 (2009) 123-130.

[2] M.W. Halterman, Neuroscience, 3rd Edition, Neurology. 64 (2005) 769--769-a. doi:10.1212/01.WNL.0000154473.43364.47.

[3] H. Asanuma, I. Rosén, Topographical organization of cortical efferent zones projecting to distal forelimb muscles in the monkey, Exp. Brain Res. 14 (1972) 243-256.

[4] C.M. Honey, V.M. Tronnier, C.R. Honey, Deep brain stimulation versus motor cortex stimulation for neuropathic pain: A minireview of the literature and proposal for future research, Comput. Struct. Biotechnol. J. 14 (2016) 234-237.

[5] S.N. Flesher, J.L. Collinger, S.T. Foldes, J.M. Weiss, J.E. Downey, E.C. Tyler-Kabara, S.J. Bensmaia, A.B. Schwartz, M.L. Boninger, R.A. Gaunt, Intracortical microstimulation of human somatosensory cortex, Sci. Transl. Med. 8 (2016) 361ra141361 ra141.

[6] K.D. Wise, J.B. Angell, A. Starr, An integrated-circuit approach to extracellular microelectrodes, IEEE Trans. Biomed. Eng. (1970) 238-247.

[7] Q. Bai, K.D. Wise, D.J. Anderson, A high-yield microassembly structure for three-dimensional microelectrode arrays, IEEE
Trans. Biomed. Eng. 47 (2000) 281-289.

[8] G. Buzsáki, Large-scale recording of neuronal ensembles, Nat. Neurosci. 7 (2004) 446.

[9] T. Kawano, T. Harimoto, A. Ishihara, K. Takei, T. Kawashima, S. Usui, M. Ishida, Electrical interfacing between neurons and electronics via vertically integrated sub- $4 \mu \mathrm{m}$-diameter silicon probe arrays fabricated by vapor-liquid-solid growth, Biosens. Bioelectron. 25 (2010) 1809-1815.

[10] D.B. Suyatin, L. Wallman, J. Thelin, C.N. Prinz, H. Jörntell, L. Samuelson, L. Montelius, J. Schouenborg, Nanowire-based electrode for acute in vivo neural recordings in the brain, PLoS One. 8 (2013) e56673.

[11] D.R. Kipke, W. Shain, G. Buzsáki, E. Fetz, J.M. Henderson, J.F. Hetke, G. Schalk, Advanced neurotechnologies for chronic neural interfaces: new horizons and clinical opportunities, J. Neurosci. 28 (2008) 11830-11838.

[12] N.A. Kotov, J.O. Winter, I.P. Clements, E. Jan, B.P. Timko, S. Campidelli, S. Pathak, A. Mazzatenta, C.M. Lieber, M. Prato, Nanomaterials for neural interfaces, Adv. Mater. 21 (2009) 39704004.

[13] J.T. Robinson, M. Jorgolli, H. Park, Nanowire electrodes for high-density stimulation and measurement of neural circuits, Front. Neural Circuits. 7 (2013) 38.

[14] J.T. Robinson, M. Jorgolli, A.K. Shalek, M.-H. Yoon, R.S. Gertner, H. Park, Vertical nanowire electrode arrays as a scalable platform for intracellular interfacing to neuronal circuits, Nat. Nanotechnol. 7 (2012) 180.

[15] C. Xie, Z. Lin, L. Hanson, Y. Cui, B. Cui, Intracellular recording of action potentials by nanopillar electroporation, Nat.

Nanotechnol. 7 (2012) 185.

[16] L. Gällentoft, L.M.E. Pettersson, N. Danielsen, J. Schouenborg, C.N. Prinz, C.E. Linsmeier, Size-dependent long-term tissue response to biostable nanowires in the brain, Biomaterials. 42 (2015) 172-183.

[17] I. von Ahnen, G. Piret, C.N. Prinz, Transfer of vertical nanowire arrays on polycaprolactone substrates for biological applications, Microelectron. Eng. 135 (2015) 52-56.

[18] J. Lee, S. Choi, S.J. Bae, S.M. Yoon, J.S. Choi, M. Yoon, Visible light-sensitive APTES-bound $\mathrm{ZnO}$ nanowire toward a potent nanoinjector sensing biomolecules in a living cell, Nanoscale. 5 (2013) 10275-10282.

[19] S.V. Puttaswamy, Q. Shi, A. Bandla, S. Kim, N. V Thakor, C. Lee, Nanowire Electrodes Integrated on Tip of Microwire for Peripheral Nerve Stimulation, J. Microelectromechanical Syst. 26 (2017) 921-925.

[20] R.D. Meyer, S.F. Cogan, T.H. Nguyen, R.D. Rauh, Electrodeposited iridium oxide for neural stimulation and recording electrodes, IEEE Trans. Neural Syst. Rehabil. Eng. 9 (2001) 2-11.

[21] S. Shin, J. Kim, J. Jeong, T.M. Gwon, G.J. Choi, S.E. Lee, J. Kim, S.B. Jun, J.W. Chang, S.J. Kim, High charge storage capacity electrodeposited iridium oxide film on liquid crystal polymer-based neural electrodes, Sens. Mater. 28 (2016) 243 260.

[22] W. Franks, I. Schenker, P. Schmutz, A. Hierlemann, Impedance characterization and modeling of electrodes for biomedical applications, IEEE Trans. Biomed. Eng. 52 (2005) 1295-1302.

[23] N.A. Peppas, Y. Huang, M. Torres-Lugo, J.H. Ward, J. Zhang, Physicochemical foundations and structural design of hydrogels in medicine and biology, Annu. Rev. Biomed. Eng. 2 (2000) 929.

[24] K. Wang, H.A. Fishman, H. Dai, J.S. Harris, Neural stimulation with a carbon nanotube microelectrode array, Nano Lett. 6 (2006) 2043-2048.

[25] S.V. Puttaswamy, A. Bandla, S.J. Fishlock, C. Lee, J. McLaughlin, A Clear, Delicate, Biocompatible Optical Window for Brain Imaging, in: 2018 IEEE 18th Int. Conf. Nanotechnol., IEEE, 2018: pp. 1-4.

[26] S.V. Puttaswarmy, A. Bandla, S.J. Fishlock, S. Lee, C. Lee, J. McLaughlin, Hydrogel as a Nerve Guide and Biocompatible Glue for Neural Applications, in: 2018 IEEE 18th Int. Conf. Nanotechnol., IEEE, 2018: pp. 1-4. 